\title{
Insights and advances in chronic urticaria: a Canadian perspective
}

\author{
Gordon Sussman ${ }^{*}$, Jacques Hébert ${ }^{2}$, Wayne Gulliver ${ }^{3}$, Charles Lynde ${ }^{1}$, Susan Waserman ${ }^{4}$, Amin Kanani ${ }^{5}$, \\ Moshe Ben-Shoshan ${ }^{6}$, Spencer Horemans', Carly Barron', Stephen Betschel', William H Yang ${ }^{7}$, Jan Dutz', \\ Neil Shear ${ }^{1}$, Gina Lacuesta ${ }^{8}$, Peter Vadas ${ }^{1}$, Kenneth Kobayashi ${ }^{7}$, Hermenio Lima ${ }^{4}$ and F Estelle R Simons ${ }^{9}$
}

\begin{abstract}
In the past few years there have been significant advances which have changed the face of chronic urticaria. In this review, we aim to update physicians about clinically relevant advances in the classification, diagnosis and management of chronic urticaria that have occurred in recent years. These include clarification of the terminology used to describe and classify urticaria. We also detail the development and validation of instruments to assess urticaria and understand the impairment on quality-of-life and the morbidity caused by this disease. Additionally, the approach to management of chronic urticaria now focuses on evidence-based use of non-impairing, non-sedating $\mathrm{H1}$-antihistamines given initially in standard doses and if this is not effective, in up to 4-fold doses. For urticaria refractory to $\mathrm{H1}$-antihistamines, omalizumab treatment has emerged as an effective, safe option.
\end{abstract}

Keywords: Chronic urticaria, Diagnosis, Classification, Management, Immunology, Antihistamines, Up-dosing, Omalizumab

\section{Introduction}

Urticaria is characterized by wheals of various sizes surrounded by flares (erythema). Mast cells play a central role in the pathophysiology. Their activation through immunologic or non-immunologic processes induces degranulation that results in release of potent preformed inflammatory mediators such as histamine, and newlysynthesized mediators such as leukotrienes and prostaglandins. The main biologic effects of these mediators are pruritus, increased vascular permeability, and tissue edema. Pruritus, the primary symptom, results from mediator-induced sensory nerve impulses travelling to the cerebrum and is associated with significant morbidity [1-3].

In this review, we provide an update on clinically relevant advances in the classification, investigations, and management of chronic urticaria that have occurred in the past few years (see list of key points for insights and advances).

\footnotetext{
* Correspondence: gsussman@rogers.com

'University of Toronto, Medicine, Toronto, ON, Canada

Full list of author information is available at the end of the article
}

\section{List of key points for insights and advances}

- The term chronic spontaneous urticaria (CSU) replaces the term chronic idiopathic urticaria (CIU).

- Second-generation non-impairing non-sedating H1-antihistamines are recommended for first-line treatment of CSU.

- Up-dosing with second-generation non-impairing non-sedating $\mathrm{H} 1$-antihistamines (to 2, 3, or 4 times the licensed dose) is recommended as second-line treatment in CSU.

- Omalizumab (anti-IgE antibody) effectively and safely induces remission in $\mathrm{H1}$-antihistamine-resistant CSU and is used as third-line treatment for this indication.

\section{Review}

Definitions, classification, and epidemiology

Acute urticaria, defined as hives lasting less than 6 weeks, can occur spontaneously, or be associated with acute viral infections or allergic reactions to foods, medications, or insect stings or bites. Chronic urticaria, defined as hives occurring intermittently for at least 6 weeks, is further classified as spontaneous, i.e. chronic spontaneous urticaria (CSU), or inducible by physical stimuli 
(Figure 1, Table 1). Spontaneous lesions are not inducible. The prevalence of CSU is $0.5 \%$ to $1 \%$ in the general population. It occurs most commonly in women, and has a peak age of onset between 20 and 40 years. There is associated angioedema, defined as asymmetric non-dependent swelling of sub-mucosal tissues, in 33\%$66 \%$ of patients with CSU [1-3] (Figure 2).

\section{Etiology and pathogenesis}

Spontaneous implies an endogenous cause; therefore, it is not surprising that in most patients with CSU, an external trigger such as an allergen cannot be identified $[1,2]$. Approximately $45 \%$ of patients have an autoimmune component associated with antibodies to the IgE receptor alpha subunit or to IgE itself on mast cell surfaces. Also, approximately $25 \%$ of CSU patients have associated thyroid auto-antibodies; however, in CSU, these antibodies do not correlate with altered thyroid function [1-3].

Patients with CSU can have high levels of anxiety. Psychiatric co-morbidities including mood, anxiety, and personality disorders have been reported [4]. These comorbidities are often major contributors to quality of life impairment [5]. It has been suggested that psychosocial factors may play a role in the pathogenesis of CSU $[4,6]$.

\section{Disease course and prognosis}

CSU, by definition, persists for at least six weeks and its course is typically characterized by exacerbations and remissions. From $10 \%$ to $50 \%$ of patients have CSU for longer than 5 years. Longer duration of illness is associated with severe disease. Elevated plasma levels of C-reactive protein, prothrombin 1 and 2, and D-dimer are reported to function as markers of CSU severity [7].

\section{Practice guidelines}

Urticaria guidelines published in 2014 include new information on CSU classification, investigations, instruments available to grade severity and impact on quality of life, as well as new recommendations for management $[2,3]$.

\section{Investigations}

Diagnosis of CSU is based on a thorough history and physical examination. Specific questioning about use of non-steroidal anti-inflammatory drugs(NSAIDs)is important because up to $30 \%$ to $50 \%$ of CSU patients have exacerbations associated with NSAID ingestion [1,2]. All patients require a complete physical examination, including visualization and confirmation of characteristic pruritic, raised erythematous lesions (Figure 1). Serial photographs are useful for documenting the extent and

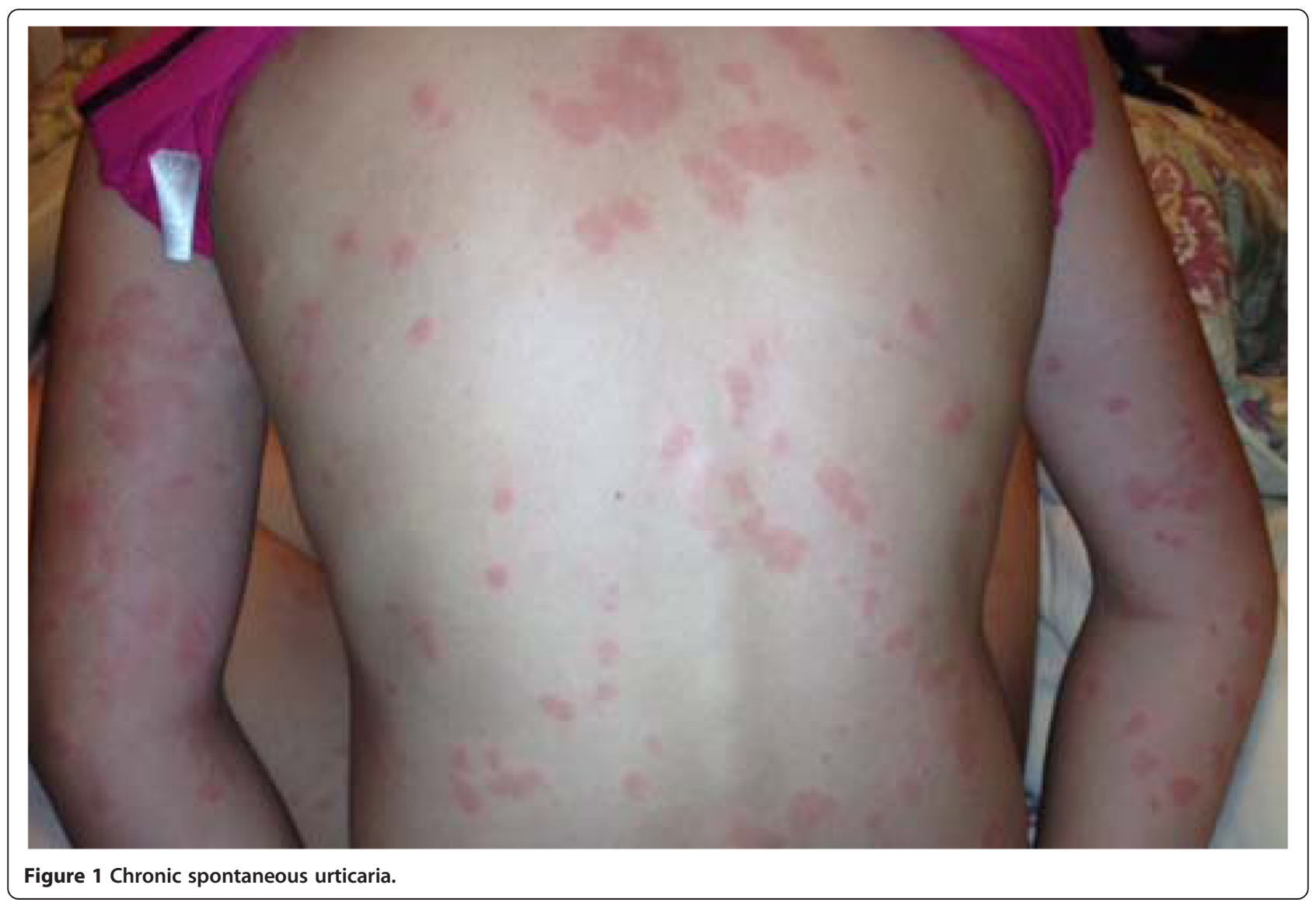


Table 1 Classification of chronic urticaria subtypes (presenting with wheals, angioedema, or both)

\begin{tabular}{lll}
\hline Acute urticaria & Chronic urticaria \\
\hline Characteristics & $\begin{array}{l}\text { Persists for less } \\
\text { than } 6 \text { weeks }\end{array}$ & Chronic spontaneous urticaria \\
& Persists for at least 6 weeks \\
& Inducible urticaria \\
& Occurs in response to an \\
& identifiable (physical) trigger. \\
& Subtypes include: \\
& - Physical urticaria (dermographism, \\
& cold urticaria, delayed pressure \\
& urticaria, solar urticaria, heat \\
& urticaria, vibratory angioedema) \\
& - Cholinergic urticaria \\
& - Contact urticaria \\
& - Aquagenic urticaria \\
\hline
\end{tabular}

severity of the urticaria. The frequency, pattern, and duration of lesions should be recorded.

Inducible urticarial lesions typically persist for less than two hours, with the exception of delayed pressure urticaria, which can last for more than 24 hours. Patients with CSU should be tested for dermographic urticaria using a tongue depressor or, if available, a standardized instrument, to stroke the skin firmly and induce wheal formation (Figure 3). Physical challenge tests for coldinduced urticaria using an ice cube or, if available, a standardized instrument, or tests for other subtypes of inducible urticaria, should be considered in patients with a history of exacerbations from these stimuli (Figure 4, Table 2).

Guidelines now recommend that the initial investigation of CSU should generally be limited to a complete blood count (CBC) and differential, and measurement of inflammation markers such as erythrocyte sedimentation rate (ESR) or C-reactive protein (CRP) [2,3] (Table 2).

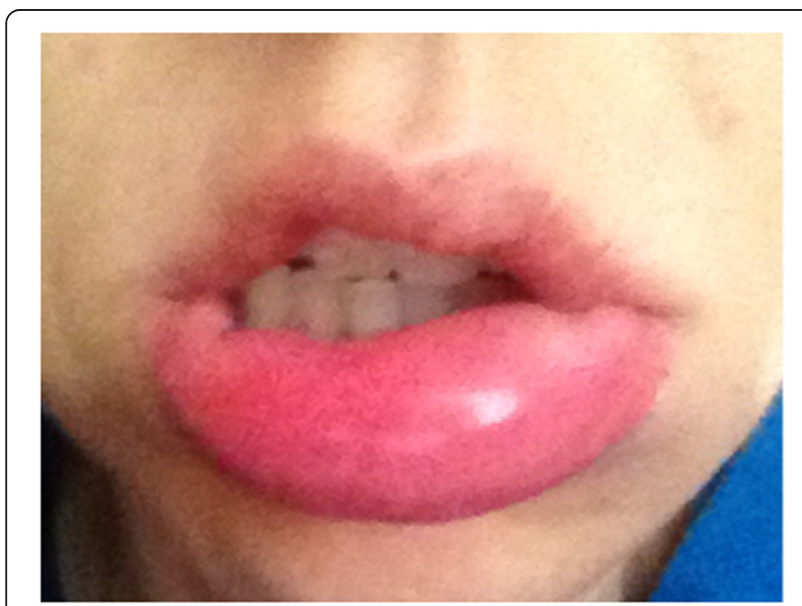

Figure 2 Angioedema.

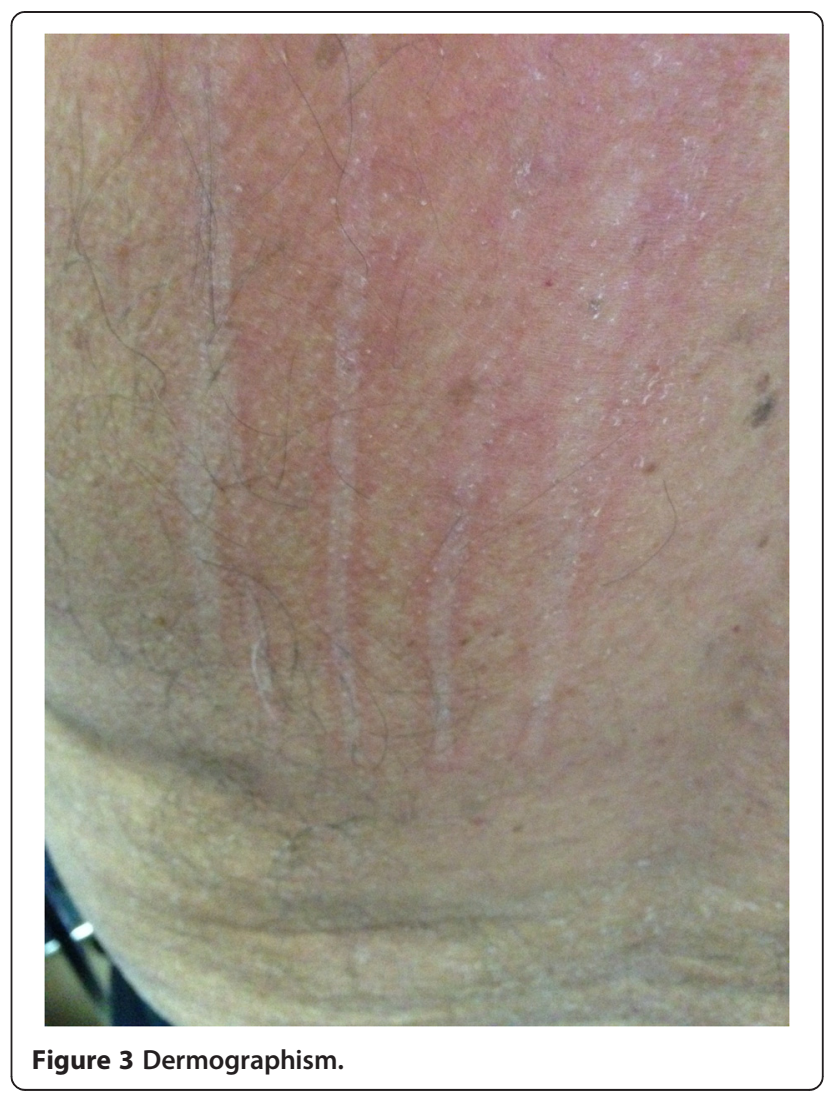

Depending on the history, other investigations may be indicated (Table 2). A skin biopsy should be performed in patients with atypical urticaria; for example, those with burning or painful hives that persist for longer than 72 hours, suggestive of urticarial vasculitis. Patients with hyperpigmented lesions should have the skin stroked firmly to elicit Darier's sign (whealing) suggestive of cutaneous mastocytosis and a baseline serum tryptase level to rule out mastocytosis; a lesional biopsy should be performed if indicated. Allergy skin tests generally have limited diagnostic value. The autologous serum skin test (ASST), performed by intradermal injection of autologous serum using careful sterile technique, is rarely used in practice. A positive ASST suggests the presence of auto-antibodies to the high-affinity IgE receptor or to IgE; however, this test is not specific for CSU [7]. Assays for auto-antibodies to the high-affinity IgE receptor or to IgE are only available in specialized research laboratories. Newer tests for auto-antibodies are being developed.

\section{Impact on quality of life}

CSU has been shown to cause significant morbidity and to have a negative impact on all aspects of a patient's life, including work, school, social activities, diet and sleep. In an attempt to quantify this, new instruments have been developed to grade urticaria severity. The Urticaria Activity Score, recorded daily for a week (UAS7), is 


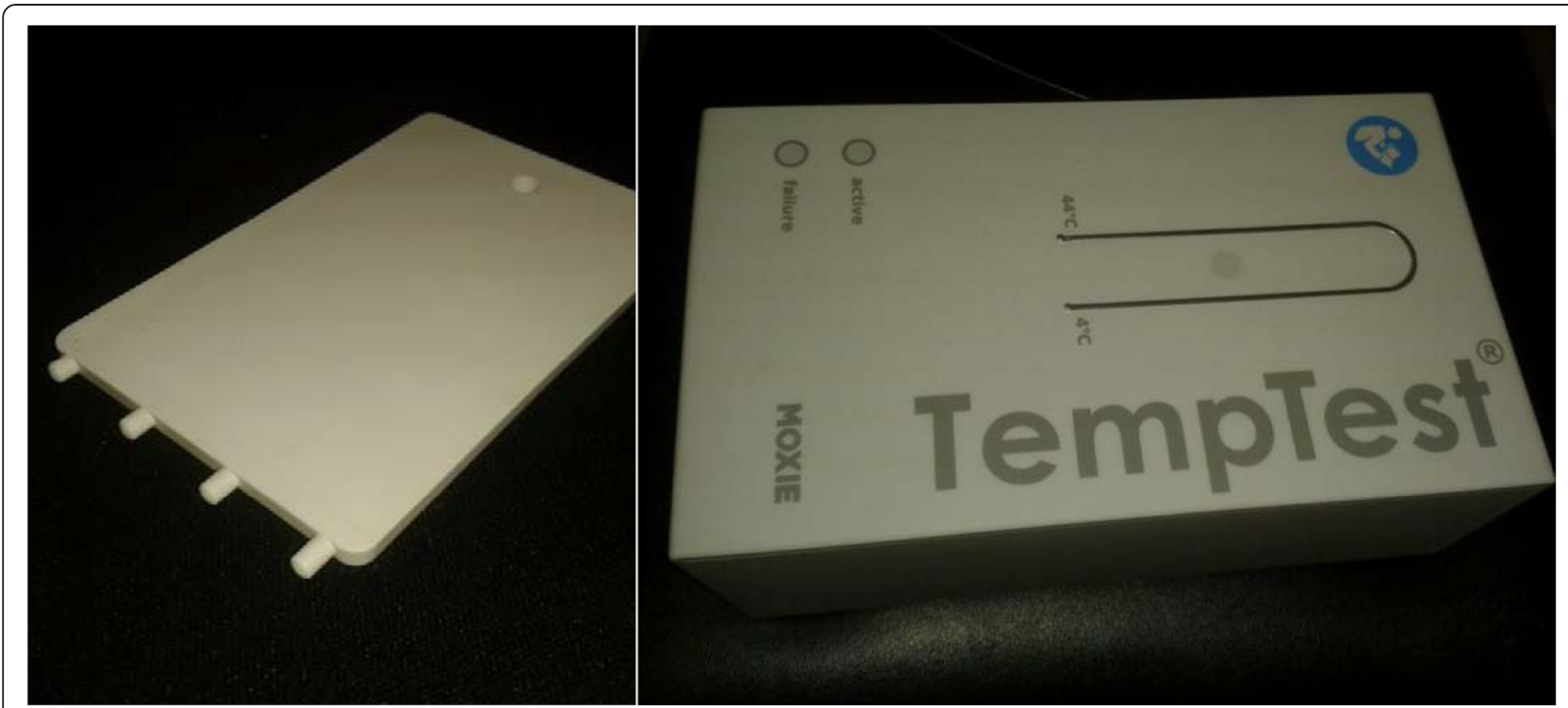

Figure 4 The dermographometer, or FricTest ${ }^{\oplus}$, (left), a standardized instrument for diagnosis of dermatographic urticaria and the TempTest $^{\circledast}$ (right) a new tool for diagnosing cold urticaria. Both instruments are produced by Moxie GmbH (Berlin, Germany).

comprised of an extent of wheals score and a pruritus score (Table 3). A UAS7 score of 6 or less is generally considered to indicate well controlled chronic urticaria. The impact of urticaria on quality of life can be assessed by a Quality of Life questionnaire (CU-Q2oL) [8], which has been validated in Canada in both English and French. Validated angioedema activity scores and a QoL score for angioedema are also available and are important tools for assessing the disability associated with disfiguring angioedema [9]. Recently, the urticaria control

Table 2 Recommended investigations in urticaria according to type and subtype

\begin{tabular}{|c|c|c|c|}
\hline Type & Subtype & Initial tests & More extensive tests \\
\hline \multirow[t]{2}{*}{ Spontaneous urticaria } & $\begin{array}{l}\text { Acute spontaneous } \\
\text { urticaria }\end{array}$ & None & None $^{*}$ \\
\hline & $\begin{array}{l}\text { Chronic spontaneous } \\
\text { urticaria }\end{array}$ & CBC with differential and ESR or CRP & $\begin{array}{l}\text { (i) Allergen skin testing, and measurement } \\
\text { of allergen-specific lgE levels are seldom } \\
\text { required in CSU. Measurement of IgG levels } \\
\text { to foods has no diagnostic value. (ii) functional } \\
\text { autoantibodies; (iii) thyroid hormones and } \\
\text { autoantibodies; (iv) physical tests; (v) tryptase; } \\
\text { (vi) autologous serum skin test; (vii) lesional } \\
\text { skin biopsy }\end{array}$ \\
\hline \multirow[t]{8}{*}{ Inducible urticaria } & Cold urticaria & $\begin{array}{l}\text { Cold provocation and threshold test: apply an } \\
\text { ice cube to the skin for } 5 \text { min, or, if available, } \\
\text { use a TempTest; urticaria appears on re-warming }\end{array}$ & CBC with differential and ESR/CRP cryoproteins \\
\hline & Delayed pressure urticaria & Pressure test & None \\
\hline & Heat urticaria & Heat provocation and threshold test & None \\
\hline & Solar urticaria & UV and visible light of different wave lengths & Rule out other light-induced dermatoses \\
\hline & $\begin{array}{l}\text { Symptomatic } \\
\text { dermographism }\end{array}$ & $\begin{array}{l}\text { Elicit dermographism by stroking skin firmly with } \\
\text { a tongue depressor or, if available, use a FricTest }\end{array}$ & None \\
\hline & Aquagenic urticaria & $\begin{array}{l}\text { Wet cloths at body temperature applied } \\
\text { for } 20 \text { min }\end{array}$ & None \\
\hline & Cholinergic urticaria & Exercise and hot bath provocation & None \\
\hline & Contact urticaria & & None \\
\hline
\end{tabular}

CBC, complete blood count; ESR, erythrocyte sedimentation rate; CRP, C-reactive protein; NSAID, non-steroidal anti-inflammatory drug.

${ }^{*}$ Acute urticaria and angioedema can also occur in the context of anaphylaxis. Such patients should be tested to allergens relevant to the history of their anaphylactic episode, eg. foods, stinging insect venoms or medications (references [2,3]). 
Table 3 The Urticaria Activity Score (UAS7) for assessing disease activity in chronic spontaneous urticaria

\begin{tabular}{lll}
\hline Score & Wheals & Pruritus \\
\hline 0 & None & None \\
1 & Mild $(<20$ wheals $/ 24 \mathrm{~h})$ & Mild (present but not annoying or troublesome) \\
2 & Moderate $(20-50$ wheals $/ 24 \mathrm{~h})$ & Moderate (troublesome but does not interfere with normal daily activity or sleep) \\
3 & Intense $(>50$ wheals $/ 24 \mathrm{~h}$ or large confluent areas of wheals) & $\begin{array}{l}\text { Intense (severe pruritus, which is sufficiently troublesome to interfere with normal } \\
\text { daily activity or sleep) }\end{array}$ \\
\hline
\end{tabular}

test (UCT) has been validated for grading severity of urticaria. This tool permits the assessment of chronic urticaria, angioedema, and inducible urticaria [10].

\section{Management}

The overall goal is complete symptom control and disease remission. Factors that exacerbate CSU, including stress and ingestion of NSAIDs should be avoided. Second-generation non-impairing non-sedating $\mathrm{H}_{1}$-antihistamines, which are effective, safe, and inexpensive, are recommended as first-line treatment. They should be taken on a regular daily basis, not on an as-needed basis. There is no advantage in using more than one $\mathrm{H}_{1}$ antihistamine at the same time (Table 4) [2,3,11,12].

Up-dosing with two, three, or four times the licensed dosage, for example, desloratadine up to $20 \mathrm{mg}$, is suggested as second-line treatment to be implemented if the licensed dosage of an $\mathrm{H}_{1}$-antihistamine is not effective [13-15].

First-generation sedating impairing $\mathrm{H}_{1}$-antihistamines are no longer recommended for use in urticaria, because they potentially interfere with restful (rapid eye movement) sleep, cause hangovers or "morning-after" effects, impair learning and memory, and reduce work efficiency. Impairment is not necessarily accompanied by sedation $[10,16]$.
Montelukast can be used as add-on second-line treatment in $\mathrm{H}_{1}$-antihistamine refractory CSU, although some clinical trials have not shown a significant benefit [17]. $\mathrm{H}_{2}$-antihistamines are no longer recommended as first-, second-, or third-line treatment, as the level of evidence supporting their use is low [18].

At any stage of treatment, a short course of an oral corticosteroid can be added on an empirical basis to provide rescue treatment of a CSU exacerbation. One example of a suggested corticosteroid treatment regimen is an initial dose of $0.3-0.5 \mathrm{mg} / \mathrm{kg}$ of prednisone or equivalent, followed by tapering of the dose in half every 3-7 days over a maximum duration of 2-4 weeks [19].

Recommended third-line treatments include omalizumab, or off-label use of cyclosporine A [2,3,17,20-25].

A trial of cyclosporine $\mathrm{A}$ is recommended as add-on treatment to a second-generation $\mathrm{H}_{1}$-antihistamine in patients who fail to respond adequately to treatment with an $\mathrm{H}_{1}$-antihistamine alone (high level of evidence). Administered in a dose of 3-5 $\mathrm{mg} / \mathrm{kg}$ divided twice daily, cyclosporine can lead to complete remission of urticaria; however, regular monitoring of blood pressure, complete blood count, and renal function, followed by dose adjustment when needed, is advised in order to reduce the possibility of toxicity [17].

\section{Table 4 Urticaria treatment algorithm}

\section{First line \\ Second-generation non-impairing non-sedating antihistamines if symptoms persist after 2 weeks \\ $\downarrow$ \\ Second-line}

Increase dosage up to four-times the standard dose $e^{1,2}$ of a second-generation non-impairing non-sedating antihistamine or, if symptoms persist after 4 further weeks, add montelukast for a 3-4 week trial

Exacerbation: oral corticosteroid

$\downarrow$

\section{Third line}

Add-on to second-line treatment: omalizumab, cyclosporine A, consider specialist referral to allergist/dermatologist. Exacerbation: oral corticosteroid
Standard dosing. Desloratadine $5 \mathrm{mg}$ OD. Loratadine $10 \mathrm{mg}$ OD. Cetirizine $\mathrm{HCl} 10 \mathrm{mg}$ OD. Fexofenadine $\mathrm{HCl} 60 \mathrm{mg} \mathrm{BID}$

Up-dosing to the limit specified, eg. Desloratadine up to $20 \mathrm{mg}$ OD. Cetirizine $\mathrm{HCl}$ up to $40 \mathrm{mg} \mathrm{OD}^{3}$. Montelukast $10 \mathrm{mg}$ OD

\section{Re-evaluate response to treatment every 3 months \\ Omalizumab 150 mg or 300 mg, SC Q4 wks. Cyclosporine A $2.5-5 \mathrm{mg} / \mathrm{kg} /$ day and taper with response}

Oral corticosteroids, for example, 0.3-0.5 mg/kg of prednisone or equivalent, followed by tapering of the dose in half every 3-7 days over a maximum duration of 2-4 weeks 
Omalizumab, an anti-IgE humanized monoclonal antibody, can be used as add-on therapy to a non-sedating second-generation $\mathrm{H}_{1}$-antihistamine as a third-line treatment for CSU (high level of evidence) [20,21]. Its efficacy and safety have been demonstrated in large, well-designed, randomized double-blind, placebo-controlled trials in patients with CSU refractory to $\mathrm{H}_{1}$-antihistamine treatment $[20,21]$. Some studies suggest that $300 \mathrm{mg}$ omalizumab injected subcutaneously every four weeks is the effective dose; however, others suggest that $150 \mathrm{mg}$ is effective [21]. Additional investigations are needed to define the optimal dose, dose schedule, and duration of treatment [24].These issues are important from a cost-effectiveness perspective. In 2014, in Canada, the United States and in Europe, omalizumab was approved by regulatory agencies for treatment of $\mathrm{H}_{1}$-antihistamine-refractory chronic urticaria in adults and adolescents age 12 years and older [25].

Use of other pharmacologic agents as third-line treatments, including hydroxychloroquine, dapsone, mycophenolate mofentil, tacrolimus, intravenous gamma-globulin and sulfasalazine, is based mainly on case reports and uncontrolled trials [15].

CSU is self-limited and eventually remits completely in most patients. Until remission occurs, whether this takes months, years, or decades, the therapeutic goal remains complete relief of itching and other symptoms.

\section{Conclusions}

The urticarias are a heterogeneous group of disorders, classified as acute or chronic (which can be spontaneous or inducible). In the new terminology, the term "spontaneous" replaces the term "idiopathic" and the term "inducible" replaces the term "physical". Chronic spontaneous urticaria (CSU) affects $0.5 \%$ to $1 \%$ of the population, and has a negative impact on all aspects of quality of life.

After the correct clinical diagnosis is made, most patients need only limited testing. Careful history, physical examination, and follow-up will identify those who require additional investigations.

Second-generation non-impairing non-sedating $\mathrm{H}_{1}$-antihistamines are recommended as first-line medications for initial treatment. New effective and safe therapeutic options have emerged for treatment of patients with CSU refractory to the standard dosage of an $\mathrm{H}_{1}$-antihistamine. Up-dosing with a second-generation non-impairing nonsedating $\mathrm{H}_{1}$-antihistamine such as desloratadine in 2,3 , or 4 times the licensed dosage is recommended as secondline treatment. Omalizumab injections subcutaneously at monthly intervals are recommended as a novel effective and safe therapeutic option for CSU refractory to the above. Research in progress will help to define some specific aspects of these new approaches and further establish their place in the treatment algorithm.

\section{Consent}

Written informed consent was obtained for publication of the accompanying images in this review. A copy of the written consent is available for review by the Editorin-Chief of this journal.

\section{Abbreviations}

CSU: Chronic spontaneous urticaria; NSAIDS: Non-steroidal anti-inflammatory drugs; CBC: Complete blood count; ESR: Erythrocyte sedimentation rate; CRP: C-reactive protein; ASST: Autologous serum skin test; UAS7: Urticaria Activity score recorded daily for a week; CU-Q2oL: Quality of Life questionnaire; UTC: Urticaria control test.

\section{Competing interests}

Dr. Sussman reports grants and personal fees from Novartis, outside the submitted work. Dr. Hebert reports personal fees from Novartis, Merck, Teva, CSL Behring, Baxter, Shire, GSK, Circassia, Pfizer, Roche, and Johnson and Johnson, outside the submitted work. Dr. Gulliver reports grants and personal fees from Novartis, outside the submitted work. Dr. Lynde reports other from Novartis, Merck, Eli Lilly, AbbVie, Amgen, Pfizer, and Stiefel/GSK, outside the submitted work. Dr. Waserman reports personal fees from Novartis, outside the submitted work. Dr. Kanani reports personal fees from Novartis, outside the submitted work. Dr. Ben-Shoshan reports personal fees from Novartis, from null, outside the submitted work. Dr. Betschel reports grants and personal fees from CSL, and personal fees from Shire, Viropharma, Baxter, Novartis, and Canadian Blood Services, outside the submitted work. Dr. Yang reports personal fees from Novartis, outside the submitted work. Dr. Dutz reports personal fees from Novartis, outside the submitted work. Dr. Kobayashi reports personal fees from Novartis, outside the submitted work.

\section{Authors' contributions}

FERS and GS played leadership roles in the project and acted to ensure the quality and coherence of this manuscript. Following a consensus meeting by all authors GS prepared the first draft of the manuscript. The other authors provided input at teleconference meetings and also provided feedback on circulated drafts of the manuscript. Following each circulation, comments and corrections were incorporated into a new draft. The final manuscript therefore results from a collaborative effort. All authors read and approved the final manuscript.

\section{Author details}

'University of Toronto, Medicine, Toronto, ON, Canada. ${ }^{2}$ Université Laval, Medicine, Quebec, QC, Canada. ${ }^{3}$ Memorial University, Medicine, Quebec, QC, Canada. ${ }^{4}$ McMaster University Medicine, Hamilton, ON, Canada. ${ }^{5}$ University of British Columbia, Medicine, Kelowna, BC, Canada. ${ }^{6}$ McGill University, Medicine, Montreal, QC, Canada. 'University of Ottawa, Medicine, Ottawa, ON, Canada. ${ }^{8}$ Dalhousie University, Medicine, Halifax, NS, Canada. ${ }^{9}$ University of Manitoba, Medicine, Winnipeg, MB, Canada.

Received: 6 December 2014 Accepted: 14 January 2015

Published online: 11 February 2015

\section{References}

1. Maurer M, Bindslev-Jensen C, Gimenez-Arnau A, Godse K, Grattan CEM, Hide $M$, et al. Chronic idiopathic urticaria is no longer idiopathic: time for an update! Br J Dermatol. 2013;168:455-6.

2. Zuberbier T, Aberer W, Asero R, Bindslev-Jensen C, Brzoza Z, Canonica GW, et al. The EAACI/GA2LEN/EDFNAO Guideline for the definition, classification, diagnosis and management of urticaria: the 2013 revision and update. Allergy. 2014;69:868-87.

3. Bernstein J, Lang D, Khan D, Craig T, Dreyfus D, Hsieh F, et al. The diagnosis and management of acute and chronic urticaria: 2014 update. J Allergy Clin Immunol. 2014;133:1270-7.

4. Uguz F, Engin B, Yilmaz EJ. Axis I and Axis II diagnoses in patients with chronic idiopathic urticaria. J Psychosom Res. 2008;64:225-9.

5. Staubach P, Eckhardt-Henn A, Dechene M, Vovend A, Metz M, Magerl M, et al. Quality of life in patients with chronic urticarial is differentially impaired and determined by psychiatric comorbidity. Br J Dermatol. 2006;154:294-8. 
6. Ben-Shoshan M, Blinderman I, Raz A. Psychosocial factors and chronic spontaneous urticaria: a systematic review. Allergy. 2013;68:131-41.

7. Rabelo-Filardi R, Daltro-Oliveira R, Campos RA. Parameters associated with chronic spontaneous urticaria duration and severity: a systematic review. Int Arch Allergy Immunol. 2013;161:197-204.

8. Baiardini I, Pasquali M, Braido F, Fumagali F, Guerra L, Compalati E, et al. A new tool to evaluate the impact of chronic urticaria on quality of life: chronic urticaria quality of life questionnaire (CU-QoL). Allergy. 2005;60:1073-8.

9. Weller K, Groffik A, Magerl M, Tohme N, Martus P, Krause K, et al. Development, validation and initial results of the Angioedema Activity Score. Allergy. 2013;68:1185-92.

10. Weller K, Groffik A, Church M, Hawro T, Krause K, Metz M, et al. Development and validation of the urticaria control test: a patient-reported outcome instrument for assessing urticaria control. J Allergy Clin Immunol. 2014;133:1365-72.

11. Simons FER, Simons $\mathrm{KJ}$. Histamine and $\mathrm{H}_{1}$-antihistamines: celebrating a century of progress. J Allergy Clinlmmunol. 2011;128:1139-50.

12. Kavosh ER, Khan DA. Second-generation $\mathrm{H}_{1}$-antihistamines in chronic urticaria: an evidence-based review. Am J ClinDermatol. 2011;12:361-76.

13. Staevska M, Popov TA, Kralimarkova T, Lazarova C, Kraeva S, Popova D, et al. The effectiveness of levocetirizine and desloratadine in up to 4 times conventional doses in difficult-to-treat urticaria. J Allergy Clinlmmunol. 2010;125:676-82.

14. Weller K, Ardelean E, Scholz E, Martus E, Zuberbier T, Maurer M. Can on-demand non-sedating antihistamines improve urticaria symptoms? A double-blind, randomized, single-dose study. Acta Derm Venereol. 2013:93:168-74.

15. Sanchez-Borges M, Caballero-Fonseca F, Capriles-Hulett A. Treatment of recalcitrant chronic urticaria with nonsedating antihistamines: is there evidence for updosing? J Investig Allergol Clin Immunol. 2013;23:141-4.

16. Church MK, Maurer M, Simons FER, Bindsley-Jensen C, van Cauwenberge $P$, Bousquet J, et al. Risks of first-generation $\mathrm{H}_{1}$-antihistamines: a GA ${ }^{2} L E N$ position paper. Allergy. 2010;65:459-66.

17. Khan DA. Alternative agents in refractory chronic urticaria: evidence and considerations on their selection and use. J Allergy Clinlmmunol Pract. 2013;1:433-40.

18. Fedorowicz $Z$, van Zuuren EJ, Hu N. Histamine $\mathrm{H}_{2}$-receptor antagonists for urticaria. Cochrane Database Syst Rev. 2012;3:CD008596.

19. Asero R, Tedeschi A. Usefulness of a short course of oral prednisone in antihistamine-resistant chronic urticaria: a retrospective analysis. J Investig Allergol Clin Immunol. 2010;20:386-90.

20. Maurer M, Rosen K, Hsieh Hsin J, Saini S, Grattan C, Gimenez-Arnau A, et al Omalizumab for the treatment of chronic idiopathic or spontaneous urticaria. N Engl J Med. 2013;368:924-35.

21. Kaplan A, Ledford D, Ashby M, Canvin J, Zazzali J, Conner E, et al. Omalizumab in patients with symptomatic chronic idiopathic/spontaneous urticaria despite standard combination therapy. J Allergy Clinlmmunol. 2013;132:101-9.

22. Sussman G, Hebert J, Barron C, Bian J, Caron-Guay R-M, Laflamme S, et al. Real-life experiences with omalizumab for the treatment of chronic urticaria. Ann Allergy Asthma Immunol. 2014;112:170-4.

23. Saini SS, Bindsley-Jensen C, Maurer M, Grob JJ, Bulbul Baskan E, Bradley MS, et al. Efficacy and safety of Omalizumab in patients with chronic idiopathic/ spontaneous urticaria who remain symptomatic on $\mathrm{H} 1$-antihistamines: A randomized, placebo-controlled study. J Invest Dermatol 2014;in press.

24. Lang DM. A critical appraisal of omalizumab as a therapeutic option for chronic refractory urticaria/angioedema. Ann Allergy Asthma Immunol. 2014;112:276-9.

25. Metz M, Ohanyan T, Church MK, Maurer M. Retreatment with omalizumab results in rapid remission in chronic spontaneous and inducible urticaria. JAMA Dermatol. 2014;150:288-90

\section{Submit your next manuscript to BioMed Central and take full advantage of:}

- Convenient online submission

- Thorough peer review

- No space constraints or color figure charges

- Immediate publication on acceptance

- Inclusion in PubMed, CAS, Scopus and Google Scholar

- Research which is freely available for redistribution 